\title{
Gene Expression Analysis of a Porcine Native Abdominal Aortic Aneurysm Model
}

\author{
Mikel Sadek, M.D. ${ }^{1}$, Robert L. Hynecek, M.D. ${ }^{2}$, Sagit Goldenberg ${ }^{2}$, K. Craig Kent, M.D. ${ }^{2}$, \\ Michael L. Marin, M.D. ${ }^{3}$, and Peter L. Faries, M.D. ${ }^{3}$ \\ 1 Department of Surgery, New York University School of Medicine \\ 2Department of Surgery, New York Presbyterian Hospital, Weill Medical College of Cornell University, \\ Columbia University College of Physicians and Surgeons
}

3Department of Surgery, Division of Vascular Surgery, Mount Sinai School of Medicine.

\section{Abstract}

Introduction-This study sought to characterize the gene expression patterns occurring during the development of aneurysms in the native porcine aorta.

Methods-In Yorkshire swine, the infrarenal aorta was balloon-dilated and infused with a solution of Type I collagenase/pancreatic porcine elastase (16000Units/1000Units). Aneurysmal and control aortic samples were obtained at one $(\mathrm{N}=3), \operatorname{two}(\mathrm{N}=6)$ and four $(\mathrm{N}=5)$ weeks following aneurysm induction. RNA was isolated, converted to biotin-modified antisense RNA and hybridized to porcine genome arrays. Aneurysmal and control gene intensities were compared using the two-sample-formeans z-test. $\mathrm{P}<0.01$ was considered statistically significant.

Results-Extracellular matrix remodeling genes that were up-regulated in aneurysmal compared to control tissue included matrix metalloproteinase-1,-2,-3,-9 and MT-MMP, cathepsin-D,-H,-K,-S, TIMP-1 and collagen I- $\alpha 1$ chain $(\mathrm{P}<0.01)$. Elastin exhibited temporally down-regulated gene expression $(\mathrm{P}<0.01)$. Inflammatory genes that were up-regulated included ICAM-2, TNF- $\alpha$, Il-1 $\beta$, Il-10, CXCR-4 and tPA $(\mathrm{P}<0.01)$. Atherosclerosis and cancer genes that were up-regulated included apoE, acyl-CoA binding protein, FLI-1 and ETS $(\mathrm{P}<0.01)$.

Conclusion-The porcine model replicates the gene expression patterns that are observed during the development of aneurysms in human studies as well as in rodent models. The porcine model thereby represents a novel method to study the impact of endovascular, cell-based and other therapeutic interventions on AAA pathophysiology.

\footnotetext{
Address for correspondence: Peter L. Faries, M.D., F.A.C.S., Chief, Division of Vascular Surgery, Mount Sinai School of Medicine, 5 East $98^{\text {th }}$ Street, Box 1273, New York, NY 10029-6574, Telephone: (212) 241-5386, Facsimile: (212) 534-4079, E-mail: peter.faries@mssm.edu.

Publisher's Disclaimer: This is a PDF file of an unedited manuscript that has been accepted for publication. As a service to our customers we are providing this early version of the manuscript. The manuscript will undergo copyediting, typesetting, and review of the resulting proof before it is published in its final citable form. Please note that during the production process errors may be discovered which could affect the content, and all legal disclaimers that apply to the journal pertain.

The following study was accepted for presentation at the 3rd Annual Academic Surgical Congress that was held from February 13-15, 2008 in Huntington Beach, CA. The enclosed manuscript has not been previously published or submitted elsewhere for publication and will not be sent to another journal until a decision is made concerning publication by SURGERY. None of the authors listed has an outside interest that conflicts with the research described, and there are no competing interests declared.
} 


\section{Introduction}

Abdominal aortic aneurysms (AAA) result from chronic degeneration of the aortic wall resulting in progressive dilatation and rupture. Current AAA therapies include surgical aneurysm repair and endovascular aneurysm repair (EVAR). EVAR has gained rapid acceptance as a minimally invasive alternative to open surgery due to diminished rates of morbidity and mortality. ${ }^{1,2}$ Despite rapid progress in the understanding of aneurysm biology, little is known about the cellular and molecular processes that occur within the aneurysm sac wall following stent-graft deployment with EVAR.

cDNA microarrays have been used to study gene expression profiles from AAA tissue obtained during surgery on humans and from aortic tissue obtained following AAA formation in small animal models. ${ }^{3,4}$ Human tissue analysis has the advantage that it most accurately reflects the biology of end-stage AAA disease. Small animal models enable investigation of the dynamic changes that occur during AAA development and allow for exploitation of transgenic methodologies.

The large animal model offers the unique ability to study AAA biology following stent-graft deployment, as well as the ability to monitor the dynamic changes that occur following AAA induction. A recently described porcine model utilizes a combination of mechanical dilatation and enzymatic degradation with a collagenase/elastase solution to create aneurysms in the native abdominal aorta. The model is characterized by gradual AAA expansion associated with degradation of aortic wall elastic fibers, an inflammatory cell infiltrate and persistent smooth muscle cell loss. ${ }^{5}$

The current study consists of a dynamic cDNA microarray analysis of the porcine native AAA model. A gene expression profile of the model serves to corroborate data obtained previously from gross anatomic and histologic analyses and to characterize similarities to data obtained from rodent models and human AAA tissue.

\section{Methods}

\section{Animal care}

The Institutional Animal Care and Use Committee approved the current protocol, and the animals were treated according to the Guide for the Care and Use of Laboratory Animals, published by the Institute for Laboratory Animal Resources Commission on Life Sciences.

\section{AAA creation}

Aneurysm creation in the porcine native AAA model was performed on male Yorkshire swine (Sus scrofus) using the technique described previously. ${ }^{5}$ Briefly, a midline abdominal incision was made, and the infrarenal abdominal aorta $(6-8 \mathrm{~mm}$ in diameter) was isolated and dissected circumferentially from the level of the renal arteries to the level of the aortic trifurcation.

Lumbar arteries originating from the isolated segment of aorta were ligated to ensure that the reagents used for AAA creation would not infiltrate the systemic circulation. Following anticoagulation with 5000 Units of heparin administered intravenously, an $8 \mathrm{~mm} \times 20 \mathrm{~mm}$ peripheral cutting balloon catheter (Boston Scientific Corporation, Natick, MA) was inserted through a vascular sheath placed in the aorta distally and then inflated to a maximum pressure of 2atmospheres over 10minutes. Subsequently, a $12-16 \mathrm{~mm} \times 20 \mathrm{~mm}$ non-compliant angioplasty balloon catheter (Boston Scientific Corporation) was gradually inflated to a maximum pressure of 2atmospheres over an additional 10minutes to initiate aortic dilatation and to augment perfusion of the aortic wall with the collagenase/elastase solution. The dilated aortic segment was then converted to a closed system by cross-clamping the aorta proximally and distally. A solution comprising Type I Collagenase 16000 Units in $10 \mathrm{~mL}$ (Worthington 
Biochemical Corporation, Lakewood, NJ) and Pancreatic Porcine Elastase 1000 Units in $110 \mathrm{~mL}$ (Sigma-Aldrich, St. Louis, MO) was infused through the introducer sheath to a maximum pressure of 1atmosphere for an additional period of twenty minutes. Subsequent to enzymatic treatment, the solution was evacuated from the aorta, and blood flow was restored. The aortotomy was closed primarily, and the abdominal wall was closed in layers. One dose of $12000 \mathrm{U}$ unfractionated subcutaneous heparin was given to the animal at the end of the case following abdominal wall closure and prior to recovery from anesthesia.

\section{RNA isolation and microarray hybridization}

AAA samples were analyzed by microarray at one $(\mathrm{N}=3)$, two $(\mathrm{N}=6)$ and four $(\mathrm{N}=5)$ weeks after AAA induction. Unmanipulated suprarenal aortic tissue served as the negative control at each time point. Tissues were immediately preserved in RNAlater solution (Applied Biosystems, Foster City, CA), snap-frozen in liquid nitrogen and pulverized for RNA extraction using the RNeasy Plus Mini Kit (Quiagen, Valencia, CA). RNA yield and purity were determined to be adequate using the 2100 Bioanalyzer (Agilent Technologies, Palo Alto, CA). RNA was amplified, reverse transcribed into double-stranded cDNA, and transcribed in vitro into biotin-modified antisense RNA (aRNA) using the Message AMP II-Biotin Enhanced Kit (Ambion, Austin, TX). The aRNA was then hybridized to GeneChip Porcine Arrays containing probes for 20,201 genes (Affymetrix).

\section{Data Analysis}

Following hybridization, each gene expression array was scanned using the GeneChip Scanner 3000 (Affymetrix), and the intensity of each probe cell was computed using GeneChip Operating Software (Affymetrix). Signal intensities were normalized to background and expressed as ratios of $\log _{2}$ (AAA gene intensity/control gene intensity). AAA and control gene expressions were compared using the two-sample-for-means $\mathrm{z}$ test. $\mathrm{P}<0.01$ was considered statistically significant.

\section{Results \\ Microarray}

20,201 genes were interrogated per porcine genome array, and on initial analysis a significant number of genes were upregulated greater than 2-fold in tissues obtained from surgically created AAAs compared to control aorta (Figure 1). In addition, an increasing number of genes were significantly upregulated with progression of aneurysm formation: 1 week (232 genes), 2 weeks (313 genes), and 4 weeks (406 genes).

Analysis of mRNA expression of genes implicated in clinical studies of AAA formation was performed at each time interval. Gene expression of extracellular matrix (ECM) modulating proteins was significantly up-regulated in AAA tissue compared to control tissue: matrix metalloproteinases (MMP-1, -2, -3, -9 and MT-MMP), cysteine proteases (Cathepsin D, H, K, $\mathrm{S})$ and the structural molecule, collagen I $\alpha 1$ chain $(\mathrm{P}<0.01)$. Tissue inhibitor of metalloproteinase-1 (TIMP-1) (a selective MMP-9 inhibitor) exhibited concomitant elevations in gene expression, consistent with the dynamic remodeling of the ECM that was observed previously on histology $(\mathrm{P}<0.01)$. Elastin, the principal component of aortic wall elastic fibers, exhibited temporally down-regulated gene expression in AAA compared to control tissue $(\mathrm{P}<0.01)$ (Figure 2).

Expression of pro-inflammatory and pro-thrombotic genes associated clinically with AAA formation was also upregulated in AAA compared to control tissue: intercellular adhesion molecule-2 (ICAM-2), tumor necrosis factor- $\alpha$ (TNF- $\alpha$ ), interleukins (Il-1 $\beta$ and Il-10), chemokine receptor-4 (CXCR-4) and tissue plasminogen activator (tPA) $(\mathrm{P}<0.01)$ (Figure 3). 
Gene expression of apolipoprotein E (ApoE) and Acyl-CoA binding protein were significantly upregulated in tissue obtained from surgically created AAAs compared to control tissue $(\mathrm{P}<$ 0.01 ), potentially representing the pathologic processes of atherosclerosis and altered fatty acid metabolism in the current model. Lastly, two oncogenes, the friend leukemia virus integration-1 (FLI-1) and E26 transformation-specific sequence (ETS) exhibited increased gene expression in AAA tissue compared to control tissue $(\mathrm{P}<0.01)$ (Figure 4).

\section{Discussion}

The porcine native AAA model exhibits reproducible aneurysm formation and is characterized histologically by an acute inflammatory response, loss of SMCs and persistent degradation of aortic wall elastic fibers. ${ }^{5}$ The current study consists of a dynamic microarray analysis designed to evaluate the gene expression changes that occur in the aortic wall following AAA induction.

The goals of the analysis were to characterize patterns of gene expression and to compare them to the anatomic and histologic changes observed during aneurysm formation in the porcine model, to compare them to data obtained from human AAA tissue as well as from small animal models, and to provide baseline data for future comparison to AAA tissue gene expression following endovascular, cell-based and other therapeutic interventions. Among the biological processes that were represented by significant alterations in gene expression, consistent patterns emerged with regards to ECM remodeling, inflammation and thrombosis, atherosclerosis and oncogene expression.

\section{ECM remodeling}

ECM degradation is believed to assume a critical role in the process of aortic wall attenuation and subsequent aneurysm formation. The MMPs are a family of zinc-dependent endopeptidases that are thought to contribute to aneurysm formation by degrading specific structural components of the ECM. Studies performed in transgenic rodent models have confirmed the functional significance of MMP-2 and MMP-9 in the process of aortic aneurysm formation. ${ }^{6-8}$ Increased MMP-9 production has also been demonstrated in tissue from human AAAs. ${ }^{4}$ Corroborating the small animal and human data, the current analysis demonstrates significantly up-regulated gene expression of MMP-2 and MMP-9 at the two- and four-week time-points, concomitant with the increased ECM degradation observed histologically. The other MMPs that are upregulated (MMP-1, MMP-3 and MT-MMP) demonstrate varied temporal patterns of expression, and further studies are required to elucidate their potential biological significance. The current model also demonstrates increased expression of several of the cysteine proteases (cathepsins- $\mathrm{D},-\mathrm{H},-\mathrm{K}$ and $-\mathrm{S}$ ) in AAA tissue. Cysteine proteases are thought to exhibit similar degenerative properties to the MMPs, and immunohistochemical studies have previously localized the over-expression of cathepsins-S and $-\mathrm{K}$ to sites of elastin damage within the vascular wall. ${ }^{9,10}$ The demonstrated lack in aneurysms of cystatin C, a cysteine protease inhibitor, further supports the functional significance of cathepsins in AAA formation. ${ }^{11}$

In addition to ECM degradation, the current study suggests that a more complex picture of ECM remodeling is occurring. TIMP-1 (selective inhibitor of MMP-9) is upregulated, suggesting that matrix degradation is not completely unopposed in the current model. Trends of elevated TIMP-1 expression have also been described in human AAA tissue, but further work is necessary to determine if the change persists at the protein level and if it is biologically relevant. ${ }^{12}$

Further evidence to support active remodeling of the ECM is demonstrated on histology in the porcine model with the increased and unregulated deposition of lamellar collagen. ${ }^{5}$ Increased gene expression over time of the collagen I $\alpha 1$ chain lends support to transcriptional regulation 
as the impetus driving increased Type I collagen production and its subsequent deposition in the aortic wall. Elastin is also examined in this study as another key component of the ECM. The histology demonstrates degradation of elastic fibers that persists throughout the histologic analysis. ${ }^{5}$ Elastin gene expression in the current model fails to up-regulate, potentially explaining the lack of elastic fiber regeneration. In addition, the continued production of Type I collagen and the abatement of elastin production have been previously observed at the protein level in tissues analyzed from human AAA specimens. ${ }^{13}$

\section{Inflammation}

Inflammation has been implicated as a significant component of the multifactorial pathogenesis that results in AAA formation. Among the inflammatory cytokines that exhibit increased gene expression in this study, up-regulation of TNF- $\alpha$, IL-1 $\beta$ and IL-10 has been demonstrated previously in tissue obtained from human AAA specimens. The inflammatory genes exhibit a peak in gene expression at two weeks, consistent with the peak inflammatory response observed histologically in the porcine model, as well as in previously described rodent models. ${ }^{3,5}$ While IL-1 $\beta$ and TNF- $\alpha$ promote the inflammatory response, IL-10 is considered to be an antiinflammatory cytokine, underscoring the complexity of the role of inflammation in aneurysm formation. 14

Chemokines, cellular adhesion molecules, thrombotic factors and other pro-inflammatory markers are increasingly being implicated in the process of AAA formation. CXCR-4 is upregulated in the current study, and prior studies have demonstrated sustained up-regulation of CXCR-2 in aneurysmal and occlusive atherosclerotic disease. ${ }^{15,16}$ Similarly, ICAM-2 is upregulated in the current study, and prior studies have implicated ICAM-1 in aortic disease. ${ }^{17}$

A recent study demonstrated that patients recruited through a AAA screening program were more likely to exhibit elevated plasma tPA levels compared to controls. ${ }^{18}$ Human tissue analysis reveals that mural thrombus lining the aneurysm sac is a potential source of circulating tPA in patients with AAAs. ${ }^{19}$ The samples from the porcine model were processed with the mural thrombus intact, potentially explaining the source of increased tPA gene expression in the current study.

\section{Atherosclerosis and oncogenesis}

A strong correlation exists between the chronic disease of atherosclerosis and the development of AAAs. ${ }^{20}$ The current model, however, does not employ an atherogenic diet and does not utilize transgenic mehthodologies to render a pig pro-atherogenic. Nonetheless, the fatty acid metabolism genes for ApoE and Acyl-CoA binding protein exhibit increased expression in AAA tissue compared to control tissue. Further studies are required to confirm that the demonstrated gene expression up-regulation translates to the protein level and that it bears functional significance either through an atherosclerotic or through a novel mechanism. The increased expression of the oncogenes FLI-1 and ETS are incompletely understood currently and warrant further investigation. Despite the unknown function of FLI-1 in aneurysm formation, a microarray analysis on human AAA tissue also demonstrates elevated FLI-1 expression, further rendering validity to the porcine model data. ${ }^{4}$

\section{Limitations}

A negative control that utilizes a sham operation with infusion of saline may add additional information with regards to the specific contributions of elastase/collagenase to the gene expression profile. However, this has been performed extensively in the rodent model, and the results have been extrapolated to the porcine model. Furthermore, this does not detract from the study results which demonstrate that the porcine model exhibits a similar gene expression profile to rodent models and to human tissue. In addition, the current study set only includes 
gene expression data for weeks one, two and four. The addition of earlier time-points might add to and refine the gene expression characterization of the model. However, earlier timepoints were not evaluated due to the concern that the gene expression patterns would reflect trauma and acute response to injury rather than AAA pathobiology.

\section{Conclusion}

Porcine models have been used advantageously to emulate various human disease states. ${ }^{21}$ In the current study, broad similarities are drawn between the porcine model, previously described rodent models and the human disease state with regards to ECM remodeling, inflammation, atherosclerosis and oncogenesis. The similarities are not absolute, and the temporal observations of RNA expression will require direct correlation with protein analysis. The porcine native AAA model is ideally suited for the deployment of a stent-graft, resulting in the unique ability to assay for aneurysm wall gene expression following endovascular, cell-based and other therapeutic interventions.

\section{Acknowledgements}

Support for research has been provided by the American Vascular Association William J. von Liebig Award in conjunction with the National Institute of Health K08HL073313.

\section{References}

1. May J, White GH, Harris JP. Complications of aortic endografting. J Cardiovasc Surg (Torino) 2005;46:359-369.

2. Towne JB. Endovascular treatment of abdominal aortic aneurysms. Am J Surg 2005;189:140-149. [PubMed: 15720980]

3. Van Vickle-Chavez SJ, Tung WS, Absi TS, Ennis TL, Mao D, Cobb JP, Thompson RW. Temporal changes in mouse aortic wall gene expression during the development of elastase-induced abdominal aortic aneurysms. J Vasc Surg 2006 May;43(5):1010-1020. [PubMed: 16678698]

4. Tung WS, Lee JK, Thompson RW. Simultaneous analysis of 1176 gene products in normal human aorta and abdominal aortic aneurysms using a membrane-based complementary DNA expression array. J Vasc Surg 2001 Jul;34(1):143-150. [PubMed: 11436088]

5. Hynecek RL, DeRubertis BG, Trocciola SM, Zhang H, Prince MR, Ennis TL, Kent KC, Faries PL. The creation of an infrarenal aneurysm within the native abdominal aorta of swine. Surgery 2007 Aug; 142(2):143-149. [PubMed: 17689678]

6. Pyo R, Lee JK, Shipley JM, Curci JA, Mao D, Ziporin SJ, et al. Targeted gene disruption of matrix metalloproteinase-9 (gelatinase B) suppresses development of experimental abdominal aortic aneurysms. J Clin Invest 2000;105:1641-1649. [PubMed: 10841523]

7. Longo GM, Xiong W, Greiner TC, Zhao Y, Fiotti N, Baxter BT. Matrix metalloproteinases 2 and 9 work in concert to produce aortic aneurysms. J Clin Invest 2002;110:625-632. [PubMed: 12208863]

8. Woodrum DT, Ford JW, Ailawadi G, Pearce CG, Sinha I, Eagleton MJ, Henke PK, Stanley JC, Upchurch GR Jr. Gender differences in rat aortic smooth muscle cell matrix metalloproteinase-9. J Am Coll Surg 2005 Sep;201(3):398-404. [PubMed: 16125073]

9. Shi G-P, Munger JS, Meara JP, Rich DH, Chapman HA. Molecular cloning and expression of human alveolar macrophage cathepsin S, an elastolytic cysteine protease. J Biol Chem 1992;267:7258-7262. [PubMed: 1373132]

10. Sukhova GK, Shi G-P, Simon DI, Chapman HA, Libby P. Expression of elastolytic cathepsins S and $\mathrm{K}$ in human atheroma and regulation of their production in smooth muscle cells. J Clin Invest 1998;102:576-583. [PubMed: 9691094]

11. Shi GP, Sukhova GK, Grubb A, Ducharme A, Rhode LH, Lee RT, et al. Cystatin C deficiency in human atherosclerosis and aortic aneurysms. J Clin Invest 1999;104:1191-1197. [PubMed: 10545518] 
12. McMillan WD, Patterson BK, Keen RR, Shively VP, Cipollone M, Pearce WH. In situ localization and quantification of mRNA for 92-kD type IV collagenase and its inhibitor in aneurysmal, occlusive, and normal aorta. Arterioscler Thromb Vasc Biol 1995;15:1139-1144. [PubMed: 7627707]

13. Rizzo RJ, McCarthy WJ, Dixit SN, Lilly MP, Shively VP, Flinn WR, Yao JS. Collagen types and matrix protein content in human abdominal aortic aneurysms. J Vasc Surg 1989 Oct;10(4):365-373. [PubMed: 2795760]

14. Middleton RK, Lloyd GM, Bown MJ, Cooper NJ, London NJ, Sayers RD. The pro-inflammatory and chemotactic cytokine microenvironment of the abdominal aortic aneurysm wall: a protein array study. J Vasc Surg 2007 Mar;45(3):574-580. [PubMed: 17321344]

15. Yamagishi M, Higashikata T, Ishibashi-Ueda H, Sasaki H, Ogino H, Iihara K, Miyamoto S, Nagaya $\mathrm{N}$, Tomoike H, Sakamoto A. Sustained upregulation of inflammatory chemokine and its receptor in aneurysmal and occlusive atherosclerotic disease: results form tissue analysis with cDNA macroarray and real-time reverse transcriptional polymerase chain reaction methods. Circ J 2005 Dec;69(12): 1490-1495. [PubMed: 16308497]

16. MacTaggart JN, Xiong W, Knispel R, Baxter BT. Deletion of CCR2 but not CCR5 or CXCR3 inhibits aortic aneurysm formation. Surgery 2007 Aug;142(2):284-288. [PubMed: 17689697]

17. Davis CA 3rd, Pearce WH, Haines GK, Shah M, Koch AE. Increased ICAM-1 expression in aortic disease. J Vasc Surg 1993 Nov;18(5):875-880. [PubMed: 7693986]

18. Wanhainen A, Nilsson TK, Bergqvist D, Boman K, Björck M. Elevated tissue plasminogen activator in patients with screening-detected abdominal aortic aneurysm. J Vasc Surg 2007 Jun;45(6):11091113. [PubMed: 17543671]

19. Houard X, Rouzet F, Touat Z, Philippe M, Dominguez M, Fontaine V, Sarda-Mantel L, Meulemans A, Le Guludec D, Meilhac O, Michel JB. Topology of the fibrinolytic system within the mural thrombus of human abdominal aortic aneurysms. J Pathol 2007 May;212(1):20-28. [PubMed: 17352452]

20. Executive Summary of The Third Report of The National Cholesterol Education Program (NCEP) Expert Panel on Detection, Evaluation, And Treatment of High Blood Cholesterol In Adults (Adult Treatment Panel III). JAMA 2001;285:2486-2497. [PubMed: 11368702]

21. Almond GW. Research applications using pigs. Vet Clin North Am Food Anim Pract 1996 Nov;12 (3):707-716. [PubMed: 8916394]

\section{Abbreviations}

AAA, Abdominal aortic aneurysm

ApoE, Apolipoprotein E

aRNA, Antisense RNA

CXCR, Chemokine receptor

ECM, Extracellular matrix

ETS, E26 transformation-specific sequence

EVAR, Endovascular aneurysm repair

FLI-1, Friend leukemia virus integration-1

$\mathrm{H}+\mathrm{E}$, Hematoxylin and eosin

ICAM, Intercellular adhesion molecule

IL, Interleukin

MMP, Matrix metalloproteinase

MRA, Magnetic resonance angiography

PMN, Polymorphonuclear

SMC, Smooth muscle cell

TIMP, Tissue inhibitor of metalloproteinase

TNF- $\alpha$, Tumor necrosis factor- $\alpha$

tPA, Tissue plasminogen activator

VVG, Verhoeff van Giesson 


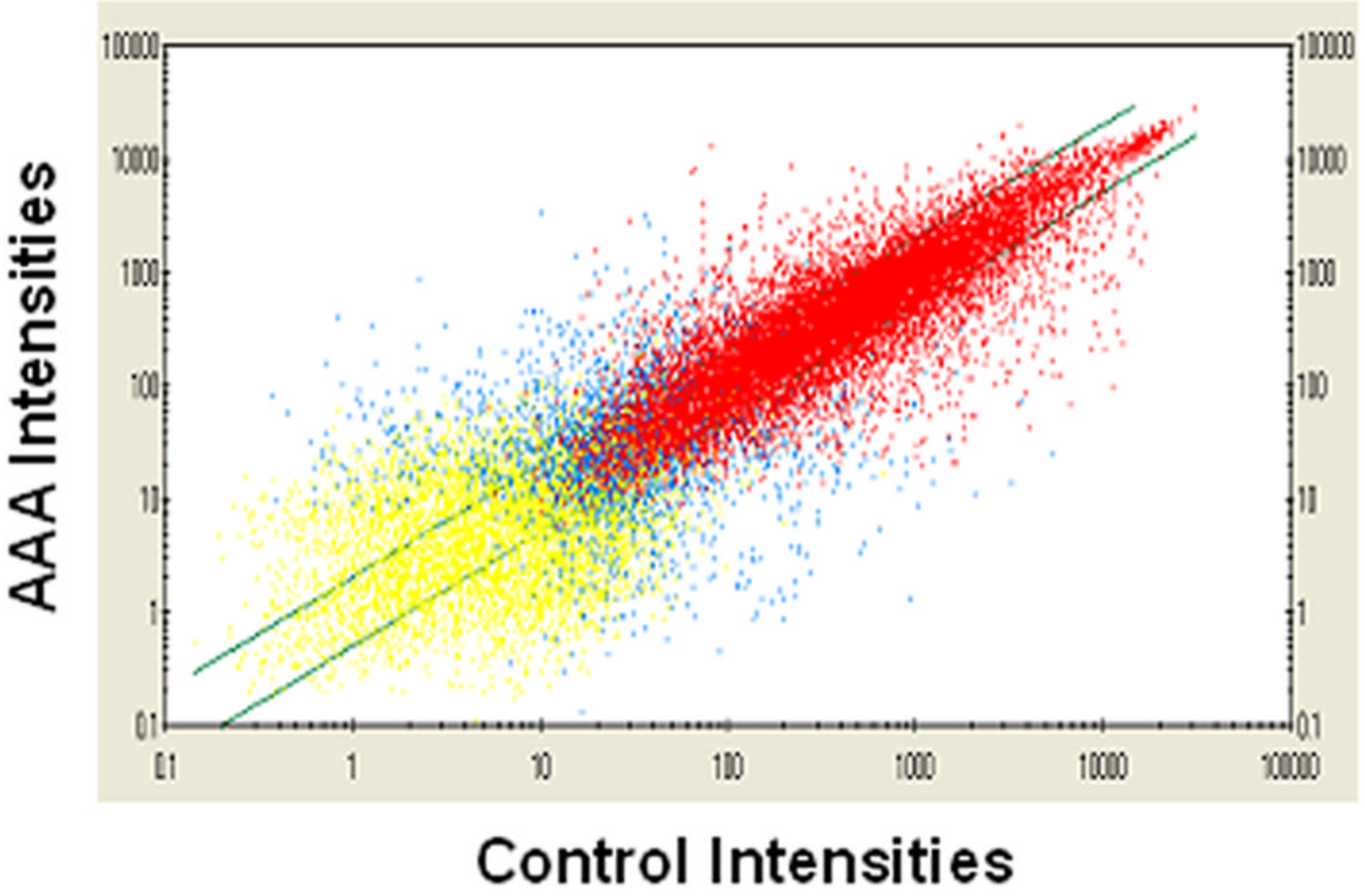

Figure 1.

Representative example of a scatter plot displaying abdominal aortic aneurysm (AAA) and control signal intensities on a logarithmic scale. Green lines indicate 2-fold changes. Red = gene present, Yellow $=$ gene absent, Blue $=$ undetermined. 
A
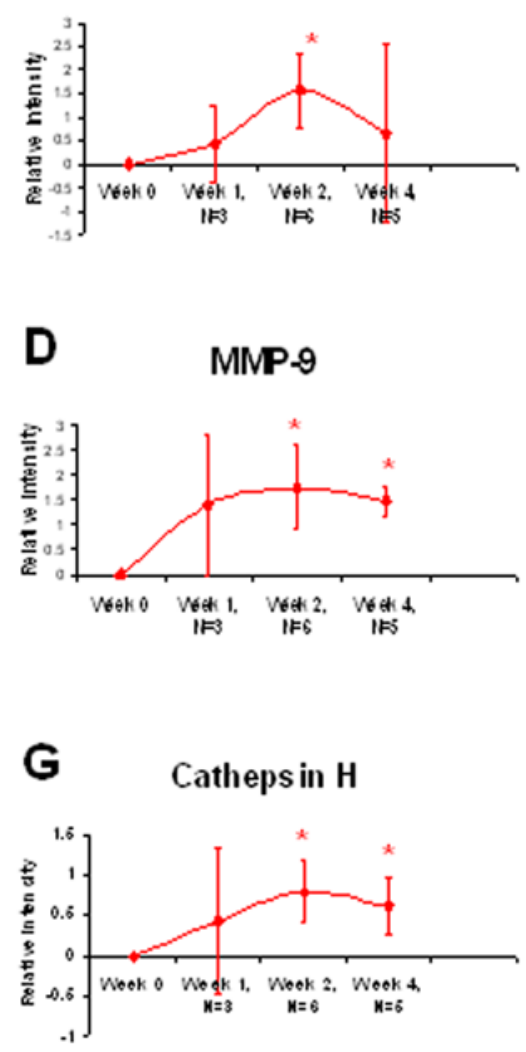

J Collagen I Alpha 1 Chain

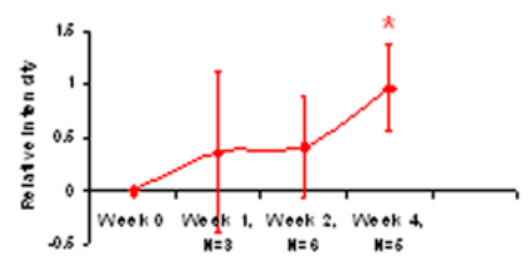

B

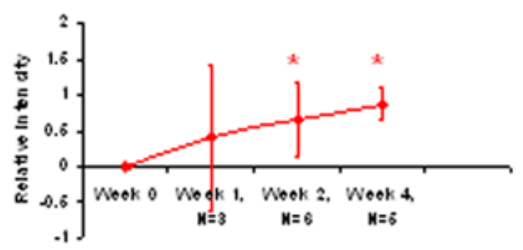

E MT-MMP-1

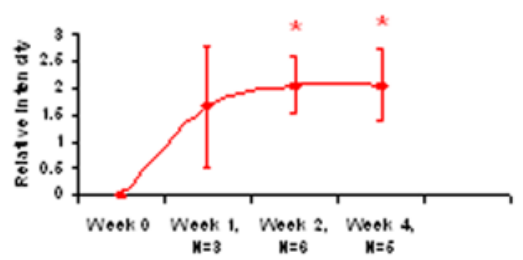

H Cathepsin $\mathrm{K}$

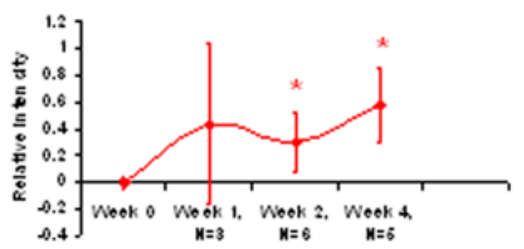

K

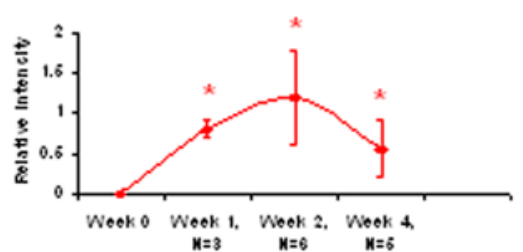

C MMP-3

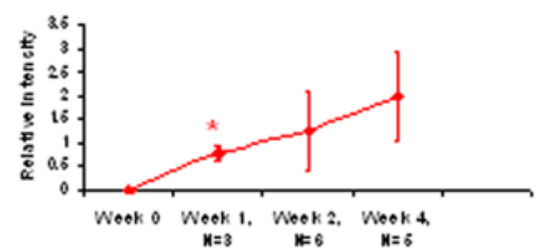

F Cathepsin D

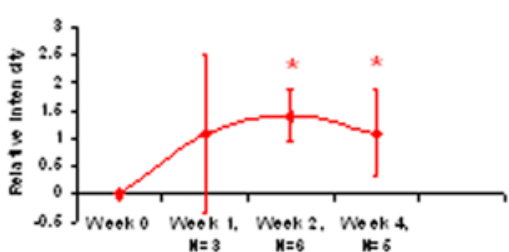

I Cathepsin S

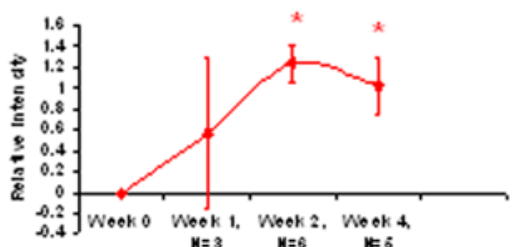

$\mathbf{L}$

Elastin

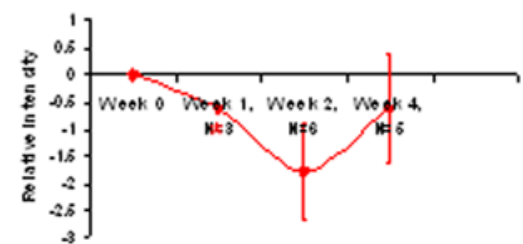

Figure 2.

Dynamic expression profiles of genes associated with extracellular matrix (ECM) modulation that exhibited significant up-regulation in abdominal aortic aneurysm (AAA) tissue compared to control tissue. (A-D) Matrix metalloproteinases (MMP-1, -2, -3, -9), (E) membrane typeMMP, (F-I) cysteine proteases (cathepsins D, H, K, S), (J) ECM structural molecule, collagen I $\alpha 1$ chain, (K) Tissue inhibitor of metalloproteinase-1 (TIMP-1), and (L) Elastin. Error bars $=$ standard deviations. Asterisks $(*)=\mathrm{P}<0.01$. 
A

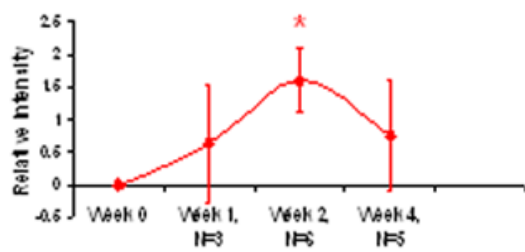

D

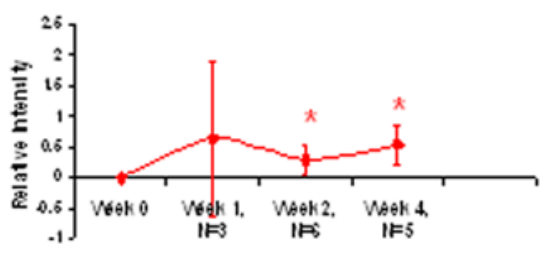

B

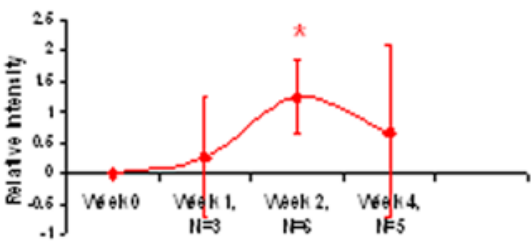

E

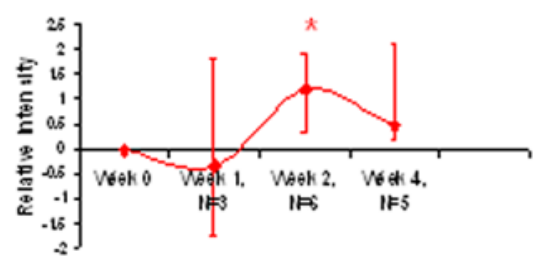

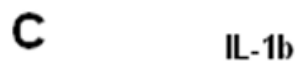

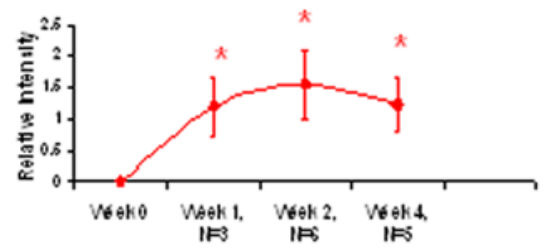

F

tPA

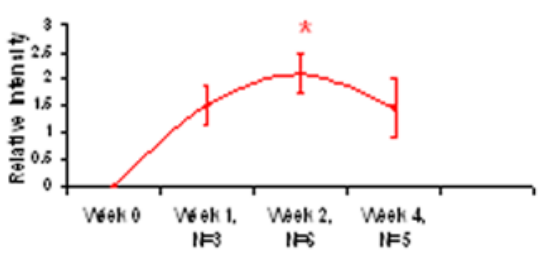

Figure 3.

Dynamic expression profiles of genes associated with inflammation that exhibited significant up-regulation in abdominal aortic aneurysm (AAA) tissue compared to control tissue. (A) Intercellular adhesion molecule-2 (ICAM-2), (B) tumor necrosis factor- $\alpha$ (TNF- $\alpha),(\mathbf{C}-\mathbf{D})$ interleukins (Il-1 $\beta$ and Il-10), (E) chemokine receptor-4 (CXCR-4), and (F) tissue plasminogen activator (tPA). Error bars $=$ standard deviations. Asterisks $(*)=\mathrm{P}<0.01$. 

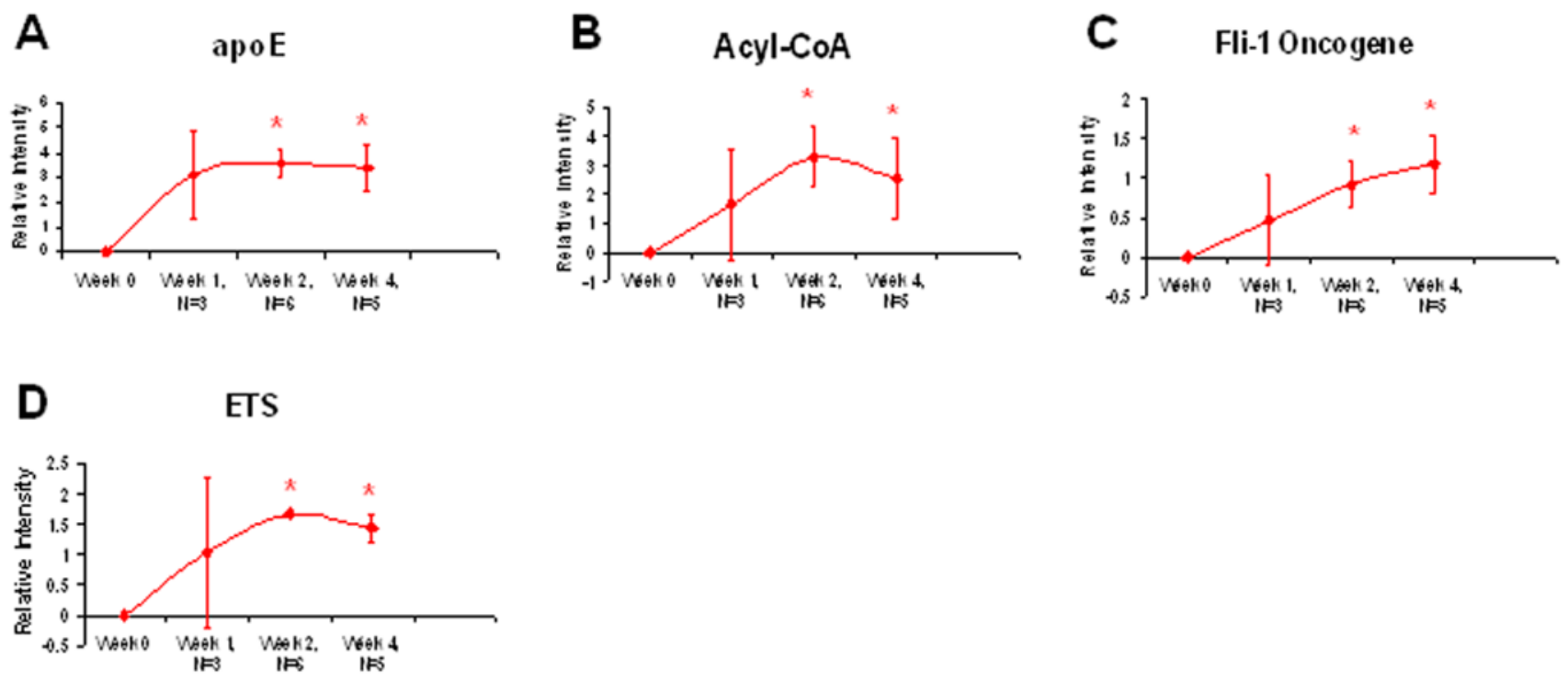

Figure 4.

Dynamic expression profiles of genes associated with atherosclerosis and cancer that exhibited significant up-regulation in abdominal aortic aneurysm (AAA) tissue compared to control tissue. (A) apolipoprotein E (ApoE), (B) Acyl-CoA binding protein, (C) friend leukemia virus integration-1 (FLI-1), and (D) E26 transformation-specific sequence (ETS). Error bars = standard deviations. Asterisks $(*)=\mathrm{P}<0.01$. 